\title{
El naufragio y la aventura intelectual: paralelismos significativos entre El Criticón y Robinson Crusoe
}

\section{Shipwreck and Intellectual Adventure: Significant Parallelisms between El Criticón and Robinson Crusoe}

\author{
Paola ENCARNACIÓN SANDOVAL \\ El Colegio de México \\ México
}

\begin{abstract}
Resumen
Este artículo estudia la relación entre el motivo del naufragio y el proceso de adquisición del lenguaje en El Criticón de Baltasar Gracián y Robinson Crusoe de Daniel Defoe. El argumento es que el naufragio se configura como un núcleo del relato propicio para desarrollar la aventura intelectual. El análisis de paralelismos entre estos textos, centrado en cuatro elementos - la intención edificante de las obras, el tratamiento del naufragio, el encuentro de los personajes y el proceso de adquisición del lenguaje-, revela una concepción peculiar de la aventura, en la cual el componente intelectual es importante para desarrollar el enfrentamiento de los personajes con sus realidades. El objetivo del estudio consiste en plantear una reflexión en torno a las inquietudes de estos autores sobre el conocimiento como parte de la aventura literaria.
\end{abstract}

Palabras clave: naufragio, lenguaje, aventura, El Criticón, Robinson Crusoe

\begin{abstract}
This paper studies the relation between the shipwreck motif and the language acquisition process in Baltasar Gracián's El Criticón and Daniel Defoe's Robinson Crusoe. The argument is that the shipwreck constitutes one core of the story that promotes the development of the intellectual adventure. The analysis of the parallelisms between these texts, focused on four elements - the edifying intention in both works, the treatment of the shipwreck, the characters meeting, and the language acquisition process - reveals a unique conception of adventure in which the intellectual component is relevant for the development of the confrontation between the characters and their realities. This study proposes a reflection about the inquisitiveness of these authors regarding knowledge as a part of literary adventure.
\end{abstract}

Keywords: shipwreck, language, adventure, El Criticón, Robinson Crusoe 
El naufragio ha sido desde los primeros testimonios literarios hasta nuestros días uno de los motivos más trascendentes de la literatura: de la Odisea a la Eneida; de la poesía latina a los relatos de náufragos en las relaciones de expediciones y conquistas imperiales o a la Tempestad de Shakespeare; y de la preponderancia del mar en la novela de aventuras del XVIII y del XIX a las reescrituras de obras con asuntos relativos al naufragio en el Xx (como Foe de Coetzee o Galápagos de Vonnegut) es indiscutible la pervivencia y fecundidad de este motivo en todas las tradiciones literarias. La singular convergencia entre miedo y fascinación que el mar reviste para el imaginario de los lectores de todas las épocas tiene que ver con el sentido universal de la aventura y con la avidez de navegar los océanos para descubrir territorios recién descubiertos.

El mar es, para la literatura, un universo con sus propias e imprevisibles reglas $\mathrm{y}$, a menudo, los personajes que se entregan a la experiencia marítima ven puesta a prueba su fortaleza física, emocional e intelectual, pues no sólo deben conocer los vientos, las mareas y los puntos cardinales, sino que también deben sobrellevar la esencia de desarraigo que los caracteriza y superar con ingenio y agudeza los infortunios que las tormentas les deparen. ${ }^{1}$ El naufragio, a la luz de lo que el mar simboliza para el discurso literario universal, es la circunstancia que cifra con mayor intensidad los peligros de la aventura marítima: por un lado, suele presentarse como un castigo a la osadía de haberse entregado al mar, en el cual el sujeto se encuentra a merced del carácter mudable de la fortuna; por otro, constituye un momento de transición entre la vida y la muerte que, sin duda, marca a los personajes que salen victoriosos de él. ${ }^{2}$

Los naufragios tienen amplias posibilidades para simbolizar la inestabilidad de la vida humana, lo cual explica su efectividad como motivo literario ${ }^{3}$ capaz de

\footnotetext{
${ }^{1}$ González Rovira (1996) en su detallado estudio sobre la tradición de la novela bizantina en España profundiza sobre esto y afirma: "el escenario marítimo aparece como uno de los marcos idóneos para la acumulación de peripecias. Una larga tradición avala esta presencia de la navegación como fuente de aventuras, empezando por la Odisea, considerada en ocasiones como la primera novela marítima. El mar atrae y repele a un mismo tiempo: es camino abierto al triunfo y al fracaso, viva imagen del destino humano hasta el punto que podemos considerarlo un cronotopo cuyo valor simbólico está íntimamente unido al del homo viator" (136).

${ }^{2}$ Habría que recordar no sólo a Ulises en la Odisea y Eneas en la Eneida sobreviven a naufragios y, a partir de ahí, inicia para ellos una nueva aventura. También Viola en Twelfth Night de Shakespeare, Gulliver en la célebre obra de Swift, el Don Juan de Byron, por mencionar algunos, son personajes en cuyo devenir incide drásticamente el naufragio.

${ }^{3}$ Vale la pena considerar la definición canónica de motivo establecida por Stith Thompson (1938): “A motif is the smallest element in a tale having a power to persist in tradition. In order to have power it must have something unusual and striking about it" (105). La visión de Thompson, aunque parte del estudio de esta unidad para la literatura folclórica, es útil para estudiar la pervivencia del naufragio como un núcleo de acción narrativo con una propia tradición. Los asedios teóricos al motivo también lo conciben como 'microtema' y consideran su recurrencia, abstracción y su potencial simbólico dentro de cada texto. Para un recorrido puntual que sintetiza las conceptualizaciones más relevantes de motivo de Thompson a Propp, LéviStrauss y Segre, véase Luna Mariscal (2017: 78-88). Una aproximación al motivo clara y contundente es la
} 
condensar diversas funciones y significados. ${ }^{4}$ Una de las funciones más relevantes del motivo del naufragio es su potencial para representar un proceso cuyo final (la salvación del náufrago) implica el inicio de una nueva aventura. ${ }^{5}$ Este punto de partida sitúa al personaje literario ante un panorama desconocido que reclama de él entereza física, ingenio y astucia para resolver conflictos prácticos; sin embargo, conlleva también un desafío emocional e intelectual en el que quien naufraga reflexiona sobre el mundo conocido, sobre su lugar en ese mundo y sobre las relaciones que establece con él. La puesta a prueba de orden intelectual que el personaje experimenta como consecuencia del naufragio es el asunto central de estas páginas.

Entre los náufragos célebres de la literatura occidental, he elegido para este estudio dos casos en los que la relación entre el naufragio y el conocimiento del mundo resulta cardinal en la apuesta literaria de sus autores: los protagonistas de El Criticón (1651-1657) de Baltasar Gracián y de Robinson Crusoe (1719) de Daniel Defoe. La razón para establecer un diálogo entre estos dos textos a partir del motivo del naufragio tiene que ver con la relevancia de esta unidad narrativa para propiciar procesos de conocimiento. Ciertamente, estas obras pertenecen a tradiciones divergentes y a distintas coordenadas temporales y geográficas $(\mathrm{y}$, por ende, literarias e ideológicas). Sin embargo, el tratamiento del naufragio en ellas da cuenta de una noción de aventura que se configura no solo a partir de desafíos

de Aurelio González (2012), quien lo entiende como "unidades menores narrativas en las cuales se expresa el significado de las secuencias fabulísticas o partes invariantes de la historia" (380). Luna (2017) incorpora a la discusión teórica de los motivos el elemento de la recepción, fundamental para comprender la pervivencia de dichas unidades. Dice Luna: “el motivo constituye así una especie de unidad gnoseológica del texto literario que permite su anclaje en la peculiar circunstancia histórica en la que surge y el establecimiento del pacto narrativo con sus receptores" (2017: 35). Estas ideas permiten que el estudio del naufragio desde la perspectiva del motivo sea productivo, ya que es posible analizar las diversas y complejas reformulaciones que los autores han ejercido sobre él a lo largo del tiempo.

${ }^{4}$ Curtius (1955) habla de la importancia de las metáforas náuticas y sus diversas formulaciones en la literatura clásica y, si bien se refiere concretamente a la metáfora y no a los motivos narrativos, importa considerar que los recursos retóricos y literarios vinculados con el mar tienen muchas posibilidades expresivas y que, sobre todo, les sirven a los poetas como puntos de partida de sus textos (189-193). También Vicente Cristóbal (2011) ha señalado a propósito de varios testimonios clásicos cómo el tratamiento literario del viaje marítimo y de la guerra son útiles para proyectar simbólicamente inquietudes humanas: "se trata de complejos temáticos que han calado tan hondo, sin duda, en la cultura occidental por la también tópica ecuación simbólica entre vida de los hombres y la guerra o el viaje: la vida es lucha, la vida es camino y travesía. Y esos dos argumentos homéricos pueden y deben entenderse también, en consecuencia, como grandes metáforas de la existencia humana, y el héroe que lucha y que viaja como un símbolo ideal de cada uno de los hombres, que tiene sus metas — particulares y compartidas — y encuentra dificultades y obstáculos para acceder a ellas" (21).

${ }^{5}$ José Manuel Herrero Massari (1997) trata el asunto y lo relaciona acertadamente con el establecimiento de un punto de partida en el trayecto del protagonista: "En la narrativa de imaginación peninsular de los Siglos de Oro, el episodio, heredero del modelo virgiliano, se convierte en un motivo habitual de la épica culta, la novela bizantina y de caballerías, e incluso de la novela picaresca [...] Se supedita a la acción principal del relato y actúa como punto de inflexión en la carrera aventurera del héroe" (206). 


\section{$24 \square$ EL NAUFRAGIO Y LA AVENTURA INTELECTUAL}

físicos y actitudes heroicas, sino que también atiende a una evolución interna de los personajes asociada al conocimiento de sí mismos, de su entorno y de sus relaciones con los otros.

En la producción literaria de Gracián, El Criticón ha sido interpretado a menudo como el punto culminante de su propuesta estética y preceptiva. En el entorno hispánico de los Siglos de Oro, el autor aragonés era más bien reconocido por sus textos morales y preceptivos (con la Agudeza y arte de ingenio a la cabeza) que por su destreza como novelista. ${ }^{6}$ El proyecto literario de El Criticón suele definirse como 'novela alegórica' o 'novela filosófica' y sus páginas delatan el influjo de la materia bizantina tan prolífica en la España de aquellos años; no en vano autores fundamentales en la tradición hispánica recurrieron a esta vertiente de asuntos peregrinos un poco antes que Gracián: Lope de Vega en El peregrino en su patria (1604), Góngora en las Soledades (1613) y Cervantes en el Persiles y Sigismunda (1617). Esta novela filosófica tiene una naturaleza alegórica, declarada en palabras del propio autor, quien pretendía "mezclar lo seco de la filosofía con lo entretenido de la invención" (Gracián, 2001: 62-63) para plantear una reflexión sobre la prudencia y la sabiduría en las etapas de la vida humana. El Criticón tuvo un largo proceso de composición pues fue publicado en tres partes (1651, 1653 y 1657) y relata la travesía de dos peregrinos, Andrenio y Critilo, en la búsqueda de Felisinda, en cuyo camino encuentran vicios y virtudes proyectados en personajes alegóricos.

La obra de Daniel Defoe, por su parte, vio la luz en 1719 y constituye un clásico de la narrativa de aventuras y el emblema por excelencia del hombre solitario en una isla. Frente al texto de Gracián, que narra una peregrinación dual, en Robinson hay una concepción del viaje y de la evolución del personaje a partir de su experiencia como náufrago cifrada en la individualidad (con todo y su encuentro con Viernes y otras interacciones humanas en la obra). En esta tónica, una de las propuestas más interesantes de Robinson es la narración en primera persona, recurso que determina la construcción de una perspectiva mucho más subjetiva y profunda. Así, el planteamiento de un sujeto capaz de rehacerse una realidad a partir de la nada, del naufragio y de enfrentarse a las adversidades de la naturaleza en un constante ejercicio de supervivencia es la huella definitoria del Robinson.

\footnotetext{
${ }^{6}$ Algunos de los críticos más notables del escritor aragonés reconocen El Criticón como una summa de los postulados preceptivos del autor. Aunque antigua, la lectura de Ricardo Senabre (1986) apunta a la prehistoria de El Criticón para la configuración de un tipo nuevo de epopeya y no de novela. Asimismo, Fernando Lázaro Carreter (1986) señala que la obra reúne recursos asociados a la agudeza que el autor había propuesto en Agudeza y arte e ingenio y que puede interpretarse como epopeya menipea. Estas pautas interpretativas apuntan al hecho de que Gracián no pretendía novelar, y esto lo ha confirmado en tiempos más recientes Aurora Egido (2006): "Gracián, como tantos otros, no supo o no quiso aprender la lección de novelar que diera Cervantes. Sus intenciones eran otras y su voluntad de estilo dista leguas de la que éste cultivara" (s. p.).
} 
La distancia que separa a la primera parte de El Criticón en 1651 de la publicación de Robinson en 1719 es de cerca de 70 años. Considerar estas fechas importa porque, pese a las diferencias geográficas y estéticas, las ideas sobre el arte y la literatura no se modifican radicalmente en virtud de un cambio de siglo pues, como ha señalado atinadamente V. Billing (2015), El Criticón es una de las propuestas más relevantes e influyentes para la literatura del XVIII en la configuración de los conflictos de un individuo moderno y su relación con el mar. La conexión entre la obra de Gracián y el Robinson, concretamente, tiene que ver, de acuerdo con Billig, con las semejanzas entre Andrenio y Viernes, pero sobre todo, con el hecho de que el texto de Defoe constituye una síntesis simplificada de la alegoría graciana. ${ }^{7}$ Por ello, es posible trazar coincidencias significativas entre un texto que testimonia la complejidad barroca como El Criticón con otro como Robinson Crusoe, que surge en un ámbito decididamente moderno en términos literarios y editoriales. ${ }^{8} \mathrm{La}$ lectura paralela de estos textos revela algunas estructuras semejantes y significativas entre las obras, como la predominante idea del viaje, el tratamiento del naufragio, la presencia de un protagonista mayor que se convierte en la figura tutelar de un personaje "aprendiz", el concepto de isla o la noción de la vida como un aprendizaje perpetuo. ${ }^{9}$ Lo interesante no consiste en la identificación de ciertos puntos de contacto entre las obras, sino en lo que este diálogo nos dice respecto a lo que el tratamiento de un motivo implica en las concepciones literarias de nuestros autores. Por ello, la hipótesis que articula el presente análisis es que la relación entre el motivo que nos ocupa y el proceso de adquisición de lenguaje en El Criticón y

\footnotetext{
${ }^{7}$ Hasta ahora, no hay aproximaciones críticas extensas respecto a las relaciones entre El Criticón y Robinson. Es posible que esto obedezca al hecho de que es difícil establecer una conexión directa entre ellas por la época, por la lengua y por las inquietudes de sus autores. Con todo, resulta sobresaliente este breve apartado que Volkmar Billig (2015) dedica al vínculo entre estos textos en su estudio "I-lands", "The Construction and Shipwreck of an Insular Subject in Modern Discourse", en el cual traza la prehistoria de la configuración literaria del hombre como una isla. Para ello, alude a testimonios literarios y filosóficos (especialmente Shakespeare y Campanella) para llegar a la segunda mitad del XVIII. Antes de Billig, Joseph Jones (1969) señala rápidamente que Andrenio es una suerte de antecesor de Robinson y halla en ambos personajes puntos en común con la figura de Abraham.

${ }^{8}$ Dice John Richetti (2001): "Defoe fue espectador de primera fila de unas transformaciones que anticipaban los modernos medios impresos de masas: la aparición en Londres, a principios del siglo XVIII, de un mercado considerable de material de lectura, y también de un nutrido público ávido de libros, folletos y periódicos en unas cantidades sin precedentes" (9).

${ }^{9}$ Maximillian Novak (2015) ha documentado un ejemplar de El Criticón en la biblioteca de Defoe: "This volume appears in the catalogue libraries of Defoe and Phillips Farewell. It might have belonged to either, or might have been thrown into sale by Oliver Payne, who arranged the religious message" (167). De acuerdo con David Fausett (1994), El Criticón fue traducido al inglés en 1681 por Paul Rycaut con el título The Critick, written originally in Spanish by Lorenzo Gracián, one of the best wits of Spain (48). Si bien estos datos resultan muy interesantes, pues apuntan a que el inglés conocía al menos en términos generales la trama de la novela alegórica de Gracián, no son suficientes para establecer entre estas obras una relación de influencia directa.
} 


\section{$26 \square$ EL NAUFRAGIO Y LA AVENTURA INTELECTUAL}

en Robinson Crusoe es un gesto patente de la función del naufragio como punto de partida de una aventura intelectual.

Al hablar de aventura, lo usual es que el imaginario de los lectores se dispare hacia situaciones arriesgadas, insólitas y, sobre todo, muy emocionantes. Esto tiene que ver con la percepción de aventura como un detonante que abre al aventurero una puerta a realidades impensadas. La perspectiva de Luis Rosales (1996) sobre lo que la aventura significa viene muy a cuento para entender el desarraigo y los procesos de aprendizaje que implica:

por su carácter de excepción, la aventura interrumpe la continuidad vital y nos impide seguir una línea de conducta determinada. La aventura es un corte, o si se quiere, una evasión hacia un mundo distinto, hacia una situación vital que no es la nuestra. Nos expropia de nuestro corazón. Y como la conducta constituye la continuidad de la existencia, al romper nuestra línea de conducta, la aventura nos expropia también de nuestra vida personal. Nos deja sin raíces. (Rosales, 1996: 225).

A la luz de estas consideraciones, los personajes centrales tanto de El Criticón como de Robinson Crusoe son un ejemplo claro de ese voluntario escape de la cotidianidad hacia una existencia llena de experiencias palpitantes y siempre cambiantes que, como veremos, no sólo se circunscriben al ámbito de la supervivencia física.

La concepción de aventura como un suceso inesperado que quiebra el orden natural de la vida de los personajes se enriquece notablemente en los dos textos aquí estudiados ya que, de la mano de la dimensión física de la aventura, los autores desarrollan procesos de conocimiento intelectual que se van entrelazando con la evolución de sus personajes. En principio, parecerían ideas opuestas: el cultivo del intelecto apunta al saber libresco que reposa en escuelas, universidades y bibliotecas en los que el estatismo y el silencio son necesarios para la reflexión. La aventura, en su sentido más tradicional, tiene un fuerte componente físico y apela a desplazamientos imprevistos y a descubrimientos de tierras, personas y situaciones que constantemente ponen en crisis al sujeto y que parecerían no exigir un solo momento de cuestionamiento. La aventura intelectual consiste así en las experiencias de conocimiento (filosóficas, reflexivas, comunicativas o artísticas) que sacan al personaje de sus vivencias habituales para enfrentarlo con nuevas y complejas realidades.

Para emprender el análisis de la relación entre naufragio y aventuras intelectuales en El Criticón y Robinson Crusoe es necesario considerar, primero, la voluntad de los autores de configurar obras edificantes; en segundo lugar, el tratamiento particular que hacen del episodio del naufragio; como tercer punto conviene hablar del encuentro entre los personajes náufragos y los personajes salvadores y el tipo de relación que se suscita entre ellos; y, por último, hay que tratar la función cardinal del lenguaje como elemento que detona un giro de aventura distinto en el curso del relato. 


\section{Intención edificante de los textos}

Gracián y Defoe hacen converger estos dos ámbitos aparentemente opuestos (la aventura física del héroe y la aventura intelectual del individuo) desde el momento en que proponen en los prólogos y dedicatorias de sus obras brindarle al lector un entretenimiento que sea a la vez edificante, el clásico delectare et prodesse horaciano. En el caso de El Criticón, la aventura cifrada en la peregrinación alegórica de los protagonistas revela que la prudencia y la sabiduría son los atributos con los que el hombre debe conducirse en cada etapa de su vida. Ya en el paratexto "A quien leyere" de la obra, dice Gracián: "Esta filosofía cortesana, el curso de tu vida en un discurso, te presento hoy, letor juizioso, no malicioso [...] He procurado juntar lo seco de la filosofía con lo entretenido de la invención, lo picante de la sátira con lo dulce de la épica..." (Gracián, 2001: 62-63). Importa de esta declaración la expresa voluntad de Gracián por usar la ficción y el deleite de los relatos para transmitir un mensaje trascendente sobre la complejidad de la vida humana.

Para los lectores habituados a los enredos cervantinos, a los lances amorosos de los textos de Lope o a la luminosidad del lenguaje gongorino, El Criticón podría resultar desconcertante. Sin embargo, el citado paratexto es importante porque anticipa el giro que el autor imprimirá sobre el concepto de peregrinación para proponer una travesía que no tiene que ver con el amor ni con la religión, sino con el profundo conocimiento del propio individuo en sus debilidades de ánimo y en su propensión a los vicios. Desde su perspectiva moralizante, el autor da cuenta desde este pórtico a la ficción, que el camino por el que atraviesan sus personajes implicará aprendizaje intelectual que puede ser equiparable a la fascinación que ejercen otro tipo de aventuras.

Desde una perspectiva muy similar, también el preludio al Robinson manifiesta el propósito edificante del texto sustentado en la ambigüedad deliberada con la que Defoe recrea al editor ficticio que legitima la obra. Dice el "Prefacio": "The Editor believes the thing to be a just History of Fact; neither is there any Appearance of Fiction in it: And however thinks, because all such things are dispatch'd, that the Improvement of it, as well to the Diversion, as to the Instruction of the Reader, will be the same; and as such, he thinks, without farther Compliment to the World, he does them a great Service in the Publication" (Defoe, 2007: 3). Es sugerente que tanto Defoe como Gracián recurren a la invención para apelar al carácter de entretenimiento de sus obras pero que asocien en todo momento un componente de enriquecimiento espiritual y una certeza de que el mensaje es provechoso en términos morales.

Si bien es cierto que estas fórmulas son habituales en los paratextos de innumerables textos literarios, hay que notar que en El Criticón y en Robinson estas declaratorias de intención de la obra forman parte de la propuesta de una aventura que hace converger la dimensión física y la dimensión espiritual: al tiempo que los personajes luchan con la naturaleza o con los obstáculos del mundo alegórico, 


\section{$28 \square$ EL NAUFRAGIO Y LA AVENTURA INTELECTUAL}

engrandecen sus espíritus y se perfilan más humanos, más críticos de su entorno. Del mismo modo, el lector que se acerca a estos textos disfruta de los deleites de la invención mientras aprende con ellos a profundizar en su condición humana.

\section{El naufragio como punto de partida}

El desarrollo de la intención edificante en las dos obras delata la preocupación ética de los autores, en la que sin duda hay una recurrente inquietud respecto a la instrucción intelectual y social del individuo. En los textos que nos ocupan, los fragmentos en los cuales se aprecia con mayor contundencia esta veta son los que tienen que ver con los procesos de adquisición de lenguaje como vía necesaria de conocimiento del mundo. Este fenómeno surge en El Criticón y en Robinson a partir del naufragio, pues sin este núcleo narrativo son inexplicables las aventuras de Critilo y Robinson, respectivamente. En cada caso, el tratamiento particular que Gracián y Defoe hacen del motivo es distinto en intenciones, en desarrollo y en amplitud e importa, de manera particular, el momento culminante del naufragio, cuando los personajes han sobrevivido a las tormentas y vislumbran un resquicio de esperanza de llegar a tierra firme.

En el texto de Gracián, el motivo se presenta según la tradición de la novela bizantina española: funciona como núcleo narrativo con el que inicia la obra (González Rovira, 1996: 138). En la formulación graciana del naufragio, los lectores no conocemos el relato de la tempestad ni la historia de vida que condujo al personaje a ese punto. Aparece en las primeras líneas de El Criticón "mal sostenido de una tabla [...] monstruo de la naturaleza y de la suerte, cisne en lo ya cano y más en lo canoro" (Gracián, 2001: 66). Critilo es el despojo vivo del naufragio y, aunque el narrador dará después algunos detalles, lo que hasta este momento sabemos es que no es joven (es canoso) y mientras trata de salvarse hace una retórica lamentación contra la audacia de hacerse a la mar (y por eso lo canoro). El condensado discurso de Critilo incorpora los clásicos tópicos de la fragilidad de la vida y de la inestabilidad del mar y, aunque breve, está recargado de ingeniosas figuras retóricas para expresar el desdichado estado del náufrago. Con todo y que resulta inverosímil que en el umbral de la muerte alguien tenga tiempo y elocuencia para quejarse de su fortuna, es muy sobresaliente la impronta del lenguaje que caracteriza al protagonista desde los primeros momentos de la historia. Gracián no pretende contar por extenso la aventura detrás del momento en que se salva el protagonista de su obra, sino hacer del naufragio el núcleo que detona un tipo de aventura que, por la destreza con las palabras que marca a Critilo, tendrá un matiz distinto a los sucesos habitualmente vividos por los náufragos de la literatura hispánica.

A la luz de este inicio parco en la descripción de tempestades pero minucioso en la proyección de las habilidades lingüísticas del protagonista, Defoe da cuenta de un gusto mucho más patente por los asuntos que emocionan al lector: la frágil 
materialidad de la embarcación, el progreso de la tormenta y el cansancio de luchar contra las mareas. Además de esto, hay un componente esencial que distingue el tratamiento de la culminación del naufragio: El Criticón tiene un narrador omnisciente y moralizante que mueve los hilos de la historia magistralmente y Robinson, en cambio, enarbola el gesto moderno de ser narrado en su totalidad por el mismo personaje que vivió esos acontecimientos. De ahí que la mirada de Robinson se dilata especialmente en el esfuerzo físico del navegante tratando de salvar su vida, y por varias páginas detalla sus habilidades de nadador, las dificultades para respirar y los golpes que recibe al impactarse con las rocas. Finalmente, logra escapar de la furia del mar:

\begin{abstract}
Now as the Waves were not so high as the first, being nearer Land, I held my Hold till the Wave abated, and the fetch's another Run, which brought me so near the Shore, that the next Wave, tho' it went over me, yet did not so swallow me up as to carry me away, and the next tun I took, I got to the main Land, where, to my great Comfort, I clamber'd up the Clifts of the Shore, and sat me down upon the Grass, free from Danger, and quite out of the Reach of the Water. (Defoe, 2017: 40)
\end{abstract}

Una vez en la playa, la atención narrativa se desplaza de la lucha corporal del individuo contra la naturaleza hacia un ámbito que privilegia la reflexión sobre la acción y alude a un importante ejercicio de conciencia en el que el temerario Robinson da gracias a Dios, no con palabras, sino con lenguaje corporal: "I walk'd about on the Shore, lifting up my Hands, and my whole Being, as I may say, wrapt up in the Contemplation of my Deliverance, making a Thousand Gestures and Motions which I cannot describe, reflecting upon all my Comrades that were drown'd, and that there should not be one Soul sav'd but myself' (Defoe, 2017: 41). Con todo y que en este pasaje el testimonio no da cuenta de que Robinson haya pronunciado una sola palabra (pues se limita a agradecer, gesticular y pensar en el destino de sus acompañantes) resulta significativo que luego del momento culminante del naufragio - con la carga de tensión física que implica salvar la vida - se abra un espacio para la reflexión y, sobre todo, para que el protagonista cobre conciencia en un momento en que es necesario mirar retrospectiva y prospectivamente. La vida no es la misma nunca después del naufragio y esta circunstancia lo enfrenta ahora con un incierto porvenir cargado de nuevas aventuras.

Con las reservas pertinentes respecto a las pautas a las que obedecen las obras según su género, su tradición y las convicciones literarias de sus autores, el punto de contacto entre El Criticón y Robinson Crusoe en el tratamiento del naufragio radica en un desarrollo del motivo que le da preponderancia como elemento que posibilita el inicio de una aventura nueva y absolutamente imprevisible y que, desde el inicio, tiene matices que apuntan a la aventura intelectual. Para Gracián, sobrevivir al naufragio representa el punto de partida para una peregrinación 


\section{$30 \square$ EL NAUFRAGIO Y LA AVENTURA INTELECTUAL}

alegórica dual cuya finalidad es encontrar la felicidad en la mesura y en la virtud. Para Crusoe, naufragar significa comenzar una vida distinta que él tendrá que construirse - literalmente - antes de tener la ocasión de emprender la travesía de vuelta a casa. En ambos casos, el fin del naufragio es la apertura de posibilidades impensadas que, tarde o temprano, exigen de los personajes la conciencia sobre su relación con el mundo, mediada necesariamente por el lenguaje.

\section{El encuentro con la otredad a partir del naufragio}

El tratamiento del naufragio como comienzo de nuevos desafíos es un recurso narrativo muy productivo en El Criticón y en Robinson. Esta circunstancia encara a los personajes a una realidad inesperada que se verá enriquecida cuando se suscite el encuentro con un individuo más joven que se convierte en ambos casos en el compañero de travesía de los protagonistas. Las versiones de Gracián y Defoe en este sentido sí son divergentes: en el texto hispánico, el encuentro entre el protagonista y el joven ocurre inmediatamente; mientras que en la obra de Defoe transcurren cerca de veinticinco años para que en el relato se encuentre Robinson con Viernes. En ambos casos, como veremos, el hallazgo del otro es un suceso que cambia el curso de las historias y, sobre todo, las relaciones de los personajes literarios con su realidad.

La obra de Gracián no deja vacíos entre el naufragio y el encuentro de Critilo con el otro porque el autor renuncia al protagonista único para apostar por una pareja protagonista, que representa para el lector dos formas distintas de vivir los problemas éticos de la peregrinación alegórica de la obra, como ya ha notado Joan Linares (2014). ${ }^{10}$ Es muy importante que este otro personaje es quien salva a Critilo del naufragio: "Fluctuando estaba entre uno y otro elemento, equívoco entre la muerte y la vida, hecho víctima de su fortuna, cuando un gallardo joven, ángel al parecer y mucho más al obrar, alargó sus braços para recogerle en ellos [...] assegurándole la dicha con la vida" (Gracián, 2001: 67).

Desde la omnisciencia del narrador, los lectores tenemos la percepción casi mística de este salvador como un ángel, quien después es llamado "restaurador de su vida" (68). Critilo exagera en muestras de gratitud hacia el joven, quien por toda respuesta "sólo daba demonstraciones de su gran gozo en lo risueño y de su mucha admiración en lo atónito del semblante [pero] a nada respondía el assombrado

\footnotetext{
${ }^{10}$ En su estudio sobre Andrenio desde la perspectiva del hombre salvaje, dice Linares (2014): “Andrenio y Critilo también se pueden ver como la personificación o la figuración plástica de dos aspectos esenciales del ser humano, que resulta así claramente considerado como un protagonista bicéfalo, un ser doble o dual, o mixto o anfibio, una especie de diptongo o un concierto de opuestos, una unidad compuesta de dos mitades, de dos yos, que se abrazan y se necesitan y se dan la vida el uno al otro, como el texto también invita a considerar" (31).
} 
isleño" (68). Como sabremos después, la razón por la que el otro no responde es que no sabe hablar; carece del medio necesario para relacionarse con su interlocutor. Con todo y las dificultades comunicativas cifradas en este inicio, a partir de este punto de la historia, los dos personajes harán el camino en pareja y se someterán en compañía al proceso de aprendizaje que implica. Sin embargo, para conocer el mundo y conocerse mutuamente es necesario que el isleño adquiera el lenguaje. El encuentro de Critilo con el otro estará definido por el aprecio y la gratitud que surgen, incluso, antes de que interactúen en el nivel discursivo.

Este encuentro tiene otros mecanismos en Robinson Crusoe porque el protagonista tuvo algunas señales (como los sueños) que le anticiparon la potencial presencia de un compañero. No obstante, desde las premoniciones, se advierte que en la relación de Robinson con Viernes hay un evidente elemento de dominación en la forma en que el protagonista percibe al joven cautivo cuando ya lo había librado de sus captores: "the poor Savage who fled, but had stopp'd; though he saw both his Enemies fallen, and kill'd, as he thought; yet was so frighted with the Fire and Noise of my Piece, that he stood Stock still, and neither came forward, which he easily understood" (Defoe, 2007: 171). A partir de ese momento, el relato abundará en las observaciones de la voz autobiográfica sobre Viernes en lo que respecta a su físico y a su docilidad, en donde sobresale el apunte sobre los rasgos "europeos" del personaje ("He had a very good Countenance, not a fierce and surly Aspect; but seem'd to have something very manly in his Face, and yet he had all the Sweetness and Softness of the european in his Countenance too, especially when he smil'd" [Defoe, 2007: 173]). Luego de "estudiar" a Viernes sin otra interacción con él que la comunicación por señas, ocurre el reconocimiento de la relación que de subordinación que tendrán estos personajes: "at lenght he came close to me, and then he kneel's down again, kiss'd the Ground, and laid his Head upon the Ground and taking me by the Foot, set my Foot upon his Head; this it seems was in token of swearing to be my Slave for ever" (Defoe, 2007: 172)

El encuentro con el otro en ambas obras va por cauces diferentes, pero coincide en un aspecto interesante: la idea de salvación. Gracián vincula con agudeza el naufragio y el enfrentamiento con el otro al hacer del personaje joven el salvador del personaje mayor y esta situación establece entre ellos un vínculo más horizontal y familiar; en cambio, en el texto de Defoe el salvado es Viernes y la gratitud eterna, además de las condiciones culturales e ideológicas, ponen a Robinson en una relación de poder (amable y de mutuo aprecio). Con las particularidades de cada caso, el enfrentamiento con el otro modifica decisivamente la concepción de la aventura de ambos personajes, pues desde este momento, la aventura se hará en compañía y en un continuo aprendizaje de los desafíos externos pero, especialmente, de la relación de los personajes con el mundo a partir de su interacción con otros individuos. El paso decisivo para enfrentar la aventura en compañía es construir un canal de comunicación eficaz y compartido. 


\section{Compartir la palabra: la adquisición del lenguaje}

Las circunstancias de cada relato ponen a los protagonistas en un papel tutelar respecto a esos otros con quienes se han encontrado, Andrenio y Viernes. Enseñar a hablar tiene un fin comunicativo, ciertamente, pero implica también muchas otras cosas: en principio, la posibilidad de compartir perspectivas, la oportunidad de comprender y, también, el placer de descubrir las capacidades del lenguaje. Tanto en El Criticón como en Robinson Crusoe el proceso de enseñar a hablar tiene un esquema que surge del choque de incomprensión con el otro, sigue con el reconocimiento de la necesidad del lenguaje, y culmina con brindarle al otro un nombre y suscitar en él el ánimo de comunicarse en una lengua común.

En El Criticón los procesos ocurren de una forma sumamente condensada: el naufragio, el rescate, la imposibilidad de comunicarse y la voluntad de enseñar a hablar. Todo está estrechamente relacionado y parece encadenado por finísimos engranes, que ayudan al lector a entender rápidamente que el protagonista en realidad es dual. Dice el narrador de la obra: "el advertido náufrago emprendió luego el enseñar a hablar al inculto joven y púdolo conseguir fácilmente favoreciéndole la docilidad y el deseo. Començó por los nombres de ambos, proponiéndole el suyo, que era el de Critilo, y imponiéndole a él el de Andrenio, que llenaron bien, el uno en lo juicioso y el otro en lo humano" (Gracián, 2001: 69). Antes de enseñarle a hablar, Andrenio debe recibir un nombre acorde con la intención alegórica del texto. Al respecto, ha señalado Emilio Hidalgo Serna (1993):

\footnotetext{
es además muy significativo y nada casual que el autor de El Criticón les diera a sus

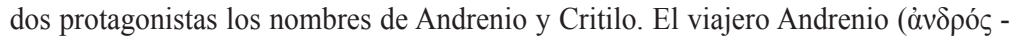
androz) personifica al "hombre privado" e individual en su tosco estado natural, con sus virtudes y limitaciones. Su acompañante, Critilo — hombre de gran discernimiento y juicio - conduce a Andrenio por el mundo como guía inteligente y agudo. (79)
}

El acto de nombrar resulta revelador en la obra en la medida en que, desde la propia etimología, los personajes estarán determinados en su actitud frente al mundo y frente al conocimiento. Como puede anticipar el lector, Andrenio es el inexperto que a menudo equivoca sus decisiones; mientras que Critilo suele ser prudente, sabio y pertinente ante las circunstancias difíciles.

En la cita de la novela, el narrador es notablemente enfático al referirse no sólo a la buena disposición del personaje para aprender a hablar (lo cual se lleva a cabo con una celeridad sorprendente) sino a la curiosidad de enterarse de la vida de Critilo y a la posibilidad de poder contar la propia. Andrenio, sabremos después, era un salvaje criado con animales en una gruta. Hasta este momento no conocía el lenguaje y ahora no sólo deberá aprenderlo en su sentido estricto, sino en la complejidad de alegorías que abundan en su peregrinación y que él mismo lleva a 
cuestas con el propio nombre. El proceso, con todo, no es tan automático y en ocasiones Andrenio debe valerse de algunos gestos para poder comunicarse efectivamente. ${ }^{11}$ Lo primero que hace cuando se siente capaz de expresarse, justamente, es contar la vida: "fuéle dando noticia de su vida a centones y a remiendos [...] mas cuando ya pudo hablar seguidamente y con igual copia de palabras a las grandezas de sus sentimientos, començó a satisfazerle desta suerte" (Gracián, 2001: 69). Después de recibir el nombre (y con ello, aprender a hablar y estar en condiciones de contar su vida), Andrenio está listo para convertirse en el peregrino alegórico que representa la inexperiencia y la paulatina acumulación de vivencias que forjan al individuo en la virtud; situaciones impensables sin la posibilidad de la palabra. ${ }^{12}$

Los procesos de adquisición de lenguaje en la relación entre Robinson y Viernes comprenden, como en El Criticón, el episodio de la imposibilidad de comunicación y del nombre, pero a estos se suma un elemento de sumisión que también está relacionado con el lenguaje. Dice Robinson:

In a little Time I began to speak to him, and teach him to speak to me; and first, I made him know his Name should be Friday, which was the Day I sav'd his Life; I call'd him so for the Memory of the Time; I likewise taught him to say Master, and then let him know, that was to be my Name; I likewise taught him to say YES and NO, and to know the meaning of them. (Defoe, 2007: 174)

También el joven cautivo siente una inclinación por el lenguaje y, aunque nunca llega a articular una historia personal plenamente estructurada (porque el discurso principal del libro es el de Robinson) es capaz de responder con suficiente información a las preguntas del náufrago:

I was greatly delighted with him and made it my Business to teach him every Thing, that was proper to make him useful, Handy, and helpful; but especially to make him speak, and understand me when I spoke, and he was the aptest Schollar that ever was, and particularly was so merry, so constantly diligent, and so pleased when he cou'd but understand me, or make me understand him, that it was very pleasant to me to talk to him, and now my Life began to be so easy. (Defoe, 2007: 177)

${ }^{11}$ Linares (2014) advierte acertadamente el desconcierto que genera en el lector la rápida y efectiva adquisición del lenguaje por parte de Andrenio: "el escritor aragonés en nada alude a las dificultades que tuvo que tener el joven Andrenio para lograr aprender a caminar sobre los pies y practicar con soltura la marcha erecta. Tanto este vacío sobre la adquisición de esa marcha, como el hecho de que la especialización ya conseguida en la comunicación con sus hermanos animales no le impidiera un aprendizaje del lenguaje humano de manera rápida y plena, subrayan la fuerte dimensión alegórica e ingeniosa de esta reconstrucción, mucho más imaginada y fabulada que atenta a proporcionar datos realistas y contrastados, o a narrar una probable y verosímil descripción de este proceso" (28).

${ }^{12}$ Hay que considerar que, como apunta Blumenberg (2004) a propósito de la adquisición del lenguaje en Andrenio, "tener lenguaje no es presupuesto para ser capaz de vivenciar la diferencia entre caverna y Universo, sino que, a la inversa, es el éxito de Critilo al enseñar a hablar a Andrenio el que se funda en que éste tenga ya tal vivencia" (376). 


\section{$34 \square$ EL NAUFRAGIO Y LA AVENTURA INTELECTUAL}

Desde que Viernes se muestra capaz de hablar con mayor fluidez, la vida de Robinson en la isla toma un giro decisivo pues la conversación lo hace sentir menos solo y conforme con su destino. De ahí que Eric Jager (1988) identifique que la aparición de Viernes en la vida de Robinson modifica decisivamente las interacciones comunicativas del náufrago: "Friday occassions several new —or renewed - functions which significantly change the solitary functions to which Crusoe has long been accustomed" (327). Gracias al aprendizaje de una lengua común, Robinson asume un papel tutelar que se amplía progresivamente hacia otros terrenos: la supervivencia en la isla, el uso de las armas, el gusto por la sal y la leche y el respeto por la vida humana, pues uno de los rasgos civilizatorios más notables es cómo Robinson convence a Viernes de dejar el canibalismo. Sin perder la esencia de bondad que lo caracteriza desde el inicio, Viernes evoluciona en su relación con el mundo a partir de la adquisición del lenguaje y muestra, con ello, cómo la conformación integral de la individualidad tienen que ver con el trabajo constante y la reflexión necesaria, como señala Billig..$^{13}$ De manera parecida al proceso de adquisición de lenguaje para Andrenio en El Criticón, en Robinson la posibilidad de compartir la palabra con Viernes es determinante para el devenir del protagonista y de la historia; poder hablar, escuchar, comprender y responder le confiere a ambos relatos una huella distinta de aventura en la que además de la dimensión física, los personajes deben probarse en una dimensión discursiva que proyecte los conflictos de su psicología.

\section{Conclusión}

Cada acercamiento de un lector a un determinado texto está siempre mediado por las experiencias previas de lectura, por las reminiscencias que ciertos fragmentos, personajes o libros enteros dejan en la memoria y que permiten el establecimiento de relaciones entre las obras. Si bien, como en el caso de El Criticón y de Robinson Crusoe, estos vínculos no siempre resultan ni tan directos ni tan evidentes, poner en diálogo estos textos es pertinente para dar cuenta de similitudes relevantes y, sobre todo, de los cuestionamientos que reposan detrás de dichas similitudes. Así, el argumento que apoyó la articulación de esta lectura paralela de algunos pasajes de las obras de Gracián y Defoe es que el tratamiento del motivo del naufragio en ambos autores funge como un punto de partida para la aventura intelectual.

Este motivo narrativo, tan fértil en la tradición literaria desde sus orígenes, suele enfrentar a los personajes a una situación desafiante y desconocida. En el

\footnotetext{
${ }^{13}$ Dice Billig (2015): "Similarly to Gracián, Defoe presents human nature as complex: while representing a certain childish state, that of Andrenio or Friday, which serves as a contrast, he underlines the human ability to reflect as necessary, as much as skill and permanent labour, in the process of becoming a complete individual and deserving owner of a private island" (25).
} 
caso de El Criticón y de Robinson es muy sobresaliente que en el tratamiento del sujeto que ha sobrevivido a la experiencia del mar y que debe hacerse un nuevo camino a partir de ese momento, exista un componente decisivo vinculado al conocimiento. El gesto más palpable en este sentido es, como hemos visto, la preponderancia del lenguaje en este enfrentamiento del personaje con un entorno nuevo, circunstancia en la cual es necesaria la palabra para interactuar con otros personajes y para comprender el entorno desde otra perspectiva. Las coincidencias que estas obras guardan entre sí tienen que ver con estructuras literarias prestablecidas (como la relación tutelar entre los personajes o el protagonismo del personaje mayor, por ejemplo); pero también hay que reconocer que estos puntos de contacto son indicativos de un fenómeno interesante en ambos textos: la propuesta de una aventura que vincula la dimensión física con la dimensión interna del personaje.

Este interés por incorporar a la visión habitual de aventura un componente asociado a la virtud y conocimiento del personaje está presente desde las líneas paratextuales tanto de la obra graciana como del texto de Defoe. En estos preliminares, los autores -incluso, en el caso de Robinson, ocultos bajo la máscara del falso editor - dan cuenta de su voluntad porque sus obras sean edificantes y esto, a la luz de su tratamiento del naufragio, refuerza la importancia de entender la aventura incorporando también la dimensión ética e intelectual de los personajes a partir de su aproximación al lenguaje. Estos son precedentes que hay que considerar en la relación crítica que ambos protagonistas tienen con la palabra, pues como hemos visto, en el caso de Gracián, Critilo se presenta como el náufrago elocuente; mientras que para Defoe, después del naufragio Robinson constantemente echa en falta el diálogo genuino.

Una de las diferencias más claras en el tratamiento del motivo en estos textos es el tiempo que transcurre para que surja el encuentro del protagonista con el otro. Si en el caso de El Criticón esto ocurre en las tres primeras "crisis" de la obra, en Robinson pasan años para que el protagonista rescate a Viernes y lo convierta en su compañero en la isla. Con todo y este detalle, tanto Critilo como Robinson escapan de la experiencia del mar para convertirse (tarde o temprano) en guías que nombran y que comparten el lenguaje con los personajes más jóvenes. Que la experiencia del naufragio los sitúe en la posición de maestro-amo podría estudiarse desde una perspectiva que considere el poder y la dominación; sin embargo, importa de esta interacción que la palabra compartida entre ambas parejas de personajes resulta determinante en el desarrollo del relato. Para El Criticón, la peregrinación alegórica sería impensable sin que Andrenio sea capaz de recibir constantemente las enseñanzas de Critilo y esto puede ocurrir únicamente porque es capaz de entenderlo; en cuando a Robinson, la presencia de Viernes en la vida del protagonista de la obra quiebra la noción del hombre solitario en constante lucha por la supervivencia pues gracias a su interacción con él, su estancia en la isla se perfila menos amenazante y más grata. 


\section{$36 \square$ EL NAUFRAGIO Y LA AVENTURA INTELECTUAL}

Estas reflexiones entre textos canónicos de la tradición hispánica e inglesa ponen de manifiesto que un motivo puede ser un material viable para articular conceptos más modernos y complejos de aventura, como las que entrañan estas obras. Habría que indagar si estos procesos se encuentran de forma semejante en otras tradiciones y en testimonios literarios más cercanos a nuestro presente; así, sería posible trazar diálogos con el influjo de estas dos obras que han tenido un sitio tan especial en sus respectivos ámbitos. Lo que Gracián y Defoe plantean con esta apuesta literaria respecto al naufragio y sus posibilidades literarias apela a un pensamiento moderno y crítico, abarcador de la experiencia del mar y del mundo; con ello, a partir de un motivo que atraviesa el tiempo y las coordenadas geográficas, establecieron caminos nuevos para pensar en una noción de aventura configurada, también, por la potencia del lenguaje.

\section{Bibliografia}

BiLLIG, Volkmar. (2015). "I-lands: The Construction and Shipwreck of an Insular Subject in Modern Discourse". En Brigitte Le Juez y Olga Springer (Eds.), Shipwreck and Island Motifs in Literature and the Arts. Leiden-Boston: BrillRodopi. 17-32.

Blumenberg, Hans. (2004). Salidos de caverna (José Luis Arántegui, Trad.). Madrid: Antonio Machado Libros.

CURTIUs, Ernst Robert. (1955). Literatura europea y Edad Media latina (Margit Frenk y Antonio Alatorre, Trad.). México: Fondo de Cultura Económica.

CRISTÓBAL, Vicente. (2011). "La tempestad como tópico literario". En Antón Alvar

(Ed.), El viaje y sus riesgos. Los peligros de viajar en el mundo grecolatino. Madrid: Liceus. 21-44

Defoe, Daniel. (2007). Robinson Crusoe. Nueva York: Oxford University Press. EGIDO, Aurora. (2006). En el camino a Roma. Cervantes y Gracián ante la novela bizantina. Alicante: Biblioteca Virtual Miguel de Cervantes. http://www.cervantesvirtual.com/nd/ark:/59851/bmcpz5m7

FAuSETT, David. (1994). The Strange Surprising Sources of Robinson Crusoe. Atlanta: Rodopi.

GoNZÁLEZ, Aurelio. (2012), "El motivo: unidad narrativa en los romances caballerescos". Revista de poética medieval, (26), 129-147.

GonZÁlez RovirA, Javier. (1996). La novela bizantina española. Madrid: Gredos. Gracián, Baltasar. (2001). El Criticón (Santos Alonso, Ed.). Madrid: Cátedra. Herrero MASSARI, José Manuel. (1997). "El naufragio en la literatura de viajes peninsular de los siglos XVI y XVII". Revista de Filología Románica, 14(2), 205-213.

Hidalgo Serna, Emilio. (1993). El pensamiento ingenioso de Baltasar Gracián (Manuel Canet, Trad.). Barcelona: Anthropos. 
JAGER, Eric. (1988). "The Parrot's Voice. Language and Self in Robinson Crusoe". Eighteenth-Century Studies, 21(3), 316-333. http://doi.org/10.2307/2738687

JONES, Joseph. (1969). "From Abraham to Andrenio: Observations on the Evolution of the Abraham Legend. Its Diffusion in Spain and Its Relation to the Theme of the Self-Taught Philosopher". Comparative Literature Studies, 6(1), 60-101.

LÁzaro CARreter, Fernando. (1986). "El género literario de El Criticón". En Actas de la I Reunión de Filólogos Aragoneses. Zaragoza: Institución "Fernando el Católico". 67-87.

LINARES, Joan. (2014). "La reinscripción del mito del hombre salvaje en El Criticón de Baltasar Gracián". Conceptos. Revista de Investigación Graciana, (11), $9-42$.

Luna MARISCAL, Karla Xiomara. (2017). El motivo literario en "El Baladro del sabio Merlín" (1498 y 1535). Con índice de motivos de "El Baladro del sabio Merlín" (Burgos, 1498 y Sevilla, 1535). México: El Colegio de México.

NovaK, Maximillian. (2015). Transformations, Ideology and the Real in Defoe's Robinson Crusoe and Other Narratives. Newark, DE: University of Delaware Press.

RichetTI, John. (2001). "Introducción”. En Daniel Defoe, Robinson Crusoe (Inga Pellisa, Trad.). México: Penguin. 9-39.

Rosales, Luis. (1996). Obras completas. Cervantes y la libertad. Madrid: Trotta.

SEnABRe, Ricardo. (1986). "El Criticón como summa retórica". En Actas de la I Reunión de Filólogos Aragoneses. Zaragoza: Institución "Fernando el Católico". 243-254.

Thompson, Stith. (1938). "Purpose and Importance of an Index of Types and Motifs". Folk-liv, 2(1), 103-108. 